\title{
Mindfulness training for adolescents: A neurodevelopmental perspective on investigating modifications in attention and emotion regulation using event-related brain potentials
}

\author{
Kevanne Louise Sanger ${ }^{1,2}$ - Dusana Dorjee ${ }^{1,2}$ \\ Published online: 7 April 2015 \\ (C) The Author(s) 2015. This article is published with open access at Springerlink.com
}

\begin{abstract}
Mindfulness training is increasingly being introduced in schools, yet studies examining its impact on the developing brain have been scarce. A neurodevelopmental perspective on mindfulness has been advocated as a powerful tool to enhance our understanding of underlying neurocognitive changes that have implications for developmental well-being research and the implementation of mindfulness in education. To stimulate more research in the developmental cognitive neuroscience of mindfulness, this article outlines possible indexes of mindfulness-based change in adolescence, with a focus on event-related brain potential (ERP) markers. We provide methodological recommendations for future studies and offer examples of research paradigms. We also discuss how mindfulness practice could impact on the development of prefrontal brain structures and enhance attention control and emotion regulation skills in adolescents, impacting in turn on their self-regulation and coping skills. We highlight advantages of the ERP methodology in neurodevelopmental research of mindfulness. It is proposed that research using established experimental tasks targeting ERP components such as the contingent negative variability, N200, error-related negativity and error positivity, P300, and late positive potential could elucidate developmentally salient shifts in the neural plasticity of the adolescent brain induced by mindfulness practice.
\end{abstract}

Kevanne Louise Sanger psp038@bangor.ac.uk

1 Centre for Mindfulness Research and Practice, Bangor University, Bangor, Gwynedd, UK

2 School of Psychology, Bangor University, Adeilad Brigantia, Bangor, Gwynedd LL57 2AS, UK
Keywords Mindfulness · Attention · Development · ERP . Emotion regulation

The term "mindfulness" was derived from the Buddhist concept of "sati," which refers to refined skills of awareness, attention, and remembering (Siegel, Germer, \& Olendzki, 2008). In the secular context, Bishop et al. (2004) proposed a two-component model of mindfulness, involving "self-regulation of attention" (maintained on immediate experience) and "attitudinal orientation" (curiosity, openness, and acceptance). They described mindfulness as a form of mental training that develops a reflective rather than reflexive mode of responding to internal and external events. Shapiro, Carlson, Astin, and Freedman (2006) later extended the model to include a third component: intention, which links back to the earlier notion of "remembering," in addition to attention and attitude (IAA). They referred to Jon Kabat-Zinn's description of mindfulness to explain their three axioms - "paying attention (Attention) in a particular way (Attitude): on purpose (Intention), in the present moment, and non-judgementally" (Kabat-Zinn, 1994, p. 4).

Several reviews have summarized the benefits of mindfulness for adult physical and mental health (Brown, Ryan, \& Creswell, 2007; Eberth \& Sedlmeier, 2012; Grossman, Niemann, Schmidt, \& Walach, 2004), in various clinical populations (Baer, 2003; Hofmann, Sawyer, Witt, \& Oh, 2010), and more recently in children, both within and outside a clinical context (Black, Milam \& Sussman, 2009; Burke, 2010; Davidson et al., 2012; Greenberg \& Harris, 2012; Meiklejohn et al., 2012; Zenner, Herrnleben-Kurz, \& Walach, 2014). The field of mindfulness research is now moving toward more rigorous clinical trials, and an increasing number of studies are targeting the underlying neurocognitive mechanisms (Bradshaw, Goldweber, Fishbein, \& Greenberg, 2012; 
Brown, Goodman, \& Inzlicht, 2013; Chiesa, Calati, \& Serretti, 2011; Hölzel et al., 2011; Lutz, Slagter, Dunne, \& Davidson, 2008; Moore \& Malinowski, 2009). Indeed, neuroscientific methods can help us understand the intricate relationship between cognition, neural plasticity, and mindfulness as a well-being-enhancing strategy. Better understanding, particularly from the neurodevelopmental perspective, may also inform the adaptation of interventions for specific populations such as adolescents, by taking into account their neurodevelopmental trajectories.

Davidson et al. (2012) outlined how contemplative practices including mindfulness could benefit young people at the interlinked levels of neural substrates, psychological functioning, and behavior. They discussed recent neurodevelopmental findings showing that social-emotional learning (SEL) programs implemented in regular school curricula improve executive function in children-for instance, in terms of inhibitory control and working memory (Greenberg \& Rhoades, 2008) - and they emphasized that mindfulness-based approaches could further strengthen SEL-like programs. Specifically in adolescents, brain areas of executive function - that is, the prefrontal cortex (PFC), where emotion regulation networks overlap with circuitry for attention control (Ochsner \& Gross, 2005; Lee, Heller, van Reekum, Nelson, \& Davidson, 2012)_require greater activation than among adults for regulating emotions. Furthermore, high-arousal situations impair adolescent decision-making abilities much more than those in adults (Steinberg, 2005). These contingencies suggest that practices like mindfulness, which enhance executive functioning (Oberle, Schonert-Reichl, Lawlor, \& Thomson, 2012; Westbrook et al., 2013), could support prefrontal brain structure development in adolescents. Arguably, such training could also enable adolescents to manage excessive levels of negative emotions like anxiety, which interfere with working memory and attention (Shackman et al., 2006; Shackman, Maxwell, McMenamin, Greischar, \& Davidson, 2011) and impact on well-being and academic performance (Kaplan, Liu, \& Kaplan, 2005). Mindfulness can also encourage a present-moment experiential form of self-awareness (ESA), as opposed to the traditional narrative form (NSA) (Davidson et al., 2012). Perceiving the self through ESA can decrease rumination and self-judgment, which in turn could benefit academic motivation and learning (Roeser \& Peck, 2009). Davidson et al. (2012) exemplified this with beliefs about intelligence - perceiving intellect as a fixed trait was associated with higher test anxiety and poorer exam results, despite cognitive ability, whereas interventions that portrayed such constructs as being malleable could reduce anxiety and increase persistence and achievement (Dweck, 2008).

In summary, the neurocognitive perspective has great potential to help expand our understanding of the developmental mechanisms of mindfulness and their implications for the adaptation and implementation of specific adolescent programs, particularly in the context of education. The purpose of this article is to formulate the theoretical foundations for mindfulness research with adolescents, which would take into account both the complexities of training this age group and their neurodevelopmental dispositions. After discussing current mindfulness training programs for adolescents, we will outline some salient methodological issues, including the advantages of event-related brain potentials (ERPs) in developmental research on mindfulness. Then we will specifically focus on the potential of neurocognitive ERP markers of attention and emotion regulation in order to study the effect of mindfulness training in adolescence.

\section{Researching mindfulness-based programs for adolescents}

Currently, several mindfulness-based programs for children and adolescents are available, which vary in their degrees of evidence-based support and their views about which aspects of mindfulness and related concepts (e.g., compassion, yoga, or cognitive behavior therapy) should be emphasized. These include Wellness Works in School (Kinder Associates LLC, 2002), Still Quiet Place (Saltzman \& Goldin, 2008), Meditación Fluir (Justo, 2009), Mindfulness-Based Stress Reduction for Teens (MBSR-T: Biegel, 2009), Mindfulness for Adolescents (Dewulf, 2009), Mindful Schools (Mindful Schools, 2010), MindUp (The Hawn Foundation, 2011), Learning to BREATHE (L2B; Broderick, 2013), and the Mindfulness in Schools Project (MiSP; Kuyken et al., 2013). For a thorough discussion of the different programs and their outcomes, see Meiklejohn et al. (2012). One overarching feature of these programs is their Western cultural focus, which needs to be carefully considered if these programs are to be adapted for use in non-Western countries and cultures. This may impact on the format and underlying intentions of implementation, such as the enhancement of attention, well-being, and academic performance in the Western context, in contrast to the encouragement of cognitive flexibility and creativity in some Asian cultures. Given the nascent nature of these programs, many of them lack strong research evidence, most having only one peer-reviewed study to support their efficacy. One of the methodologically strongest studies conducted so far was by Biegel, Brown, Shapiro, and Schubert (2009), who evaluated the MBSR-T intervention with young people receiving community mental health support. The study followed a randomized controlled design, including a posttreatment follow-up and diagnostic assessments by a study-blind clinician. The participants in the training group significantly improved on levels of anxiety, perceived stress, and depression by the 3-month follow-up, and also showed diagnostic improvements. Hopefully, more future studies will apply as robust a design as this trial, 
while also integrating neurocognitive assessments that have not so far been employed.

It is also important to consider the contribution of participant-specific variables to the outcomes of studies with adolescents. For example, the significant findings in Biegel et al. (2009) could have been impacted by the clinical nature of the sample - a variable that needs to be taken into account in future research with nonclinical populations in schools where the ceiling effect may decrease the likelihood of finding improvements. Indeed, Gould, Dariotis, Mendelson, and Greenberg (2012) reported just this, finding that baseline depression scores moderated mindfulness-training effects in urban youths. This highlights the need for measures that would be sensitive enough to detect changes in both clinical and nonclinical groups - which is where neurocognitive assessments can be particularly helpful. In addition to the clinicalnonclinical differences, personality traits have been found to impact on the outcomes of mindfulness training with adolescents. Specifically, Huppert and Johnson (2010) reported that agreeableness and openness significantly correlated with improvements in well-being after MiSP training. In addition, nonreactivity has been reported to directly moderate the beneficial effects of mindful observing on anxiety and depression (Desrosiers, Vine, Curtiss, \& Klemanski, 2014). Age may also play a role; Schonert-Reichl and Lawlor (2010) found in their early validation study of MindUp (previously known as Mindfulness Education) that the course was more effective with younger students.

Two other issues for consideration are the amount of home practice necessary for a significant effect and the required qualifications of a program's trainers. One of the most prevalent adult-based mindfulness training programs is Mindfulness-Based Stress Reduction (MBSR; Kabat-Zinn, 1990), which involves eight 2.5 -h sessions and asks participants to individually practice for $45 \mathrm{~min}$ daily. These requirements are reduced in most youth mindfulness programs, but there is still a strong emphasis on regular practice, if only for 5-10 min per day. It is currently not clear how the amount of home practice impacts on outcomes with this population. Foret et al. (2012) trained 11th-grade students (16-17 years old) in a 4-week relaxation curriculum including mindfulness and breathing meditation. After the intervention, the pupils reported significant improvements in their stress management skills, perceived stress, and state anxiety. These promising results were found in a group in which $80 \%$ either never logged on to the website for their home practice or only completed it once. However, Huppert and Johnson (2010) found that home practice was a significant contributing factor to mindfulness and well-being effects after MiSP training. The latter intervention was run with a younger (14-15 years), allmale cohort. It is possible that younger adolescents who are less matured neurologically and behaviorally, or boys, who are known to have a slower developmental trajectory
(Brumback, Arbel, Donchin, \& Goldman, 2012), need this additional practice. Methodologically, home practice is a pivotal issue, given that it may have a significant impact on intervention effects (Zenner et al., 2014), but is difficult to record accurately. Researchers have typically relied on selfreport measures, but the use of ID-locked online home practices (e.g., Foret et al., 2012) or a similar tracking system is a potential solution. More reliable measures would enable us to fully review the extent of home-practice contributions and allow program designers to balance intervention efficacy with time effectiveness.

In terms of trainer qualification requirements, few studies rigorously report on the mindfulness training and qualifications of the program teachers. Most mindfulness-based programs for adolescents involve external trainers, normally a program's developers, communicating the mindfulness course to pupils (e.g., Broderick \& Metz, 2009; Huppert \& Johnson, 2010; Kuyken et al., 2013; Raes, Griffith, Van der Gucht, \& Williams, 2014). But if mindfulness programs prove effective enough to be considered for broad implementation into school curricula, mindfulness training and delivery will need to become more self-sustaining. Most education boards cannot afford to pay external trainers in the long term, but without upholding the fidelity of the program, any attempts at training young people may be fruitless. An alternative model would involve training school teachers in mindfulness, supporting them to develop a personal practice, and then training them in the delivery of mindfulness-based curricula (e.g., the model developed and used by the Centre for Mindfulness Research, $\&$ Practice, 2014). It seems that a compromise between these two delivery approaches could be met, in order to achieve a program that all schools could practically accommodate without weakening the therapeutic outcomes.

\section{Methodological issues of neurodevelopmental research on mindfulness with adolescents}

Bradshaw et al. (2012) evaluated the theoretical aspects of developmental neuroscience that could help shape schoolbased preventative interventions - developmental research on reward pathways, stress, social-cognitive mechanisms, and executive functioning seem particularly relevant here. They concluded that mindfulness-based programs could help promote regulatory processes if they were taught within the education system. However, preliminary studies with children, including two systematic reviews, only reported low to moderate effects (Black et al., 2009; Burke, 2010; Flook et al., 2010). In comparison, meta-analysis reports in adults, evaluating 8-week courses in MBSR (Kabat-Zinn, 1990) or mindfulness-based cognitive therapy (MBCT; Segal, Williams, \& Teasdale, 2002), have found medium to high effect sizes on various measures of mindfulness, well-being, 
negative affect, and so forth (Grossman et al., 2004; Hofmann, Sawyer, Witt, \& Oh, 2010). This could, in part, result from the developmentally appropriate reductions to course length and depth, as well as in practice frequency and duration, seen in child mindfulness programs. In this context, the adolescent age group may be a more advantageous research population than younger children, bridging the gap between adult and child mindfulness-based curricula. Adolescence can also be seen as a late catchment point for neurocognitive interventions within the context of prefrontal development (Spear, 2013), with mindfulness training particularly targeting attentionmonitoring and control systems of the PFC (Hölzel et al., 2011).

Spear (2013) also advocated for adolescent-related governmental policy to take more consideration of developmental neuroscience. This position was based on the emerging consensus among researchers that adolescents' perceptions of rewarding and aversive stimuli are strongly biased toward the former, and that the role of context is highly influential over their decision-making abilities. Spear reviewed recent fMRI research and nonhuman animal models that demonstrated that adolescents are susceptible to "hot cognitions," in which the still-maturing prefrontal cortex can process cognitive tasks at adult levels of performance but can also be overridden by more-matured subcortical brain regions of the dopaminergic, mesolimbic reward pathway, like the ventral striatum. This shift in activation can result in greater risk-taking behaviors (Gardner \& Steinberg, 2005). Spear ends by proposing that developmental neuroscience could help introduce interventions that actively support the development of prefrontal brain regions, thus balancing adolescent perceptions of reward and punishment in order to prevent extreme risk-taking. Mindfulness-based training could be a helpful intervention in this context, particularly if it can be sustainably implemented in schools.

The introduction of developmental neurocognitive approaches into mindfulness training and research requires careful consideration of suitable research tools. Investigations of neurocognitive mechanisms in adults have so far mostly relied on functional and structural magnetic resonance imaging (MRI; see Hölzel et al., 2011), and to a lesser extent on ERPs, which are averaged brain waves in response to certain categories of stimuli, such as oddballs or affective pictures (Fabiani, Gratton, \& Coles, 2000). Each of the two methods has its pros and cons, with MRI having superior spatial resolution, and thus being more suitable for research questions about localization, and ERPs providing millisecond temporal accuracy of neurocognitive processing, which is advantageous for questions tapping into automatic versus controlled processing. Another strength of MRI is its longer-standing use in mindfulness research, so that the grounding for further developments is already established. Although less frequently used in mindfulness research so far, the ERP methodology has the advantage of being less costly and theoretically more firmly established, after more than 60 years of research. Importantly, ERP research has identified functionally specific indexes of neurocognitive processing, so called ERP components, which can be used in the assessment of attention control and efficiency, inhibition, semantic processing, and error judgment. In addition, ERPs can be particularly helpful in the investigation of skill acquisition effects, where fMRI findings focusing on localization may mask functionally salient changes in processing efficiency induced by learning (Dorjee \& Bowers, 2012). Nevertheless, developmental factors must be taken into account if one is using either approach. ERP components have typically been described in adult populations, whereas the limited child research has indicated different scalp localizations and time courses in the stilldeveloping brain. Please refer to Table 1 for studies in which these differences are also known to apply in adolescence. The following ERP components seem particularly relevant to neurocognitive research on mindfulness with adolescents:

1. The contingent negative variation $(\mathrm{CNV})$ is a slowbuilding negative waveform that emerges in the period between a warning and imperative stimulus. It has a frontal/central distribution and signals preparatory motor activity, sensory anticipation, and the activation of attention (Walter, Cooper, Aldridge, McCallum, \& Winter, 1964).

2. The visual $\mathrm{N} 200$ (N2) is a negative deflection with a frontal/central distribution, which signals task-specific inhibition (Falkenstein, Hoormann, \& Hohnsbein, 1999) and conflict monitoring (Ladouceur, Dahl, \& Carter, 2007). It can also be detected at occipital sites (Fabiani et al., 2000).

3. The $\mathrm{P} 300$ ( $\mathrm{P} 3$ family of positive components) is elicited in response to salient stimulus events, thus allocating mental resources to attention and memory operations associated with stimulus processing (Polich, 2007).

4. Two subcomponents of the P300, the P3a and P3b, have been distinguished. Whereas the $\mathrm{P} 3 \mathrm{a}$ has a fronto-central distribution and is associated with automatic attention capture (Polich, 2007), the P3b has a centro-parietal distribution and has been linked to stimulus categorization and processing, as well as to an updating of working memory (Sutton, Braren, Zubin, \& John, 1965).

5. The error-related negativity (ERN) is a negative deflection over fronto-central sites, used to assess automatic responses to an error that deviates from goal-directed behavior (Falkenstein, Hohnsbein, Hoormann, \& Blanke, 1991). This is followed by the error positivity (Pe), which is sensitive to the subsequent appraisal of that an error's severity (Overbeek, Nieuwenhuis, \& Ridderinkhof, 2005).

6. The late positive potential (LPP) is considered a neural marker of emotional arousal, reflecting the preferential 
processing and encoding of motivationally relevant stimuli. It is a slow-building positive waveform with a central/ posterior distribution (Brown et al., 2013).

7. The late positive complex (LPC) is a positive, broadpeaking waveform with a parietal distribution. It has been associated with deep processing (Rellecke, Sommer, \& Schacht, 2012), memory recall (Schaefer, Pottage, \& Rickart, 2011) and affective rumination (Sitges et al., 2007).

We will discuss each of these components in relation to the effects of mindfulness on attention and emotion processing in adolescents in the following sections.

\section{Mindfulness training effects on attention}

Attention is a key modulator of cognitive processing, enabling us to select task-relevant stimuli and inhibit irrelevant information, sustain focus on cognitive performance, divide attention, and stay vigilant when needed. One theory of attention that is commonly used in mindfulness research proposes that there are three largely independent attention networks (Petersen \& Posner, 2012; Posner \& Petersen, 1990). The orienting network supports selecting relevant sensory input and shifting attention toward a goal-related stimulus (disengaging and reengaging attention). The alerting network refers to a level of arousal and vigilance - that is, the ability to maintain sensitivity to external stimuli. This can be further separated into phasic alertness, which is task-specific, and intrinsic alertness, which refers to more general trait levels of arousal. Finally, executive attention monitors and resolves any conflicts arising between thought, emotion, and action (Raz \& Buhle, 2006). Executive attention is typically measured by using tasks involving an incompatibility between different aspects of a task, otherwise known as "conflict," such as in the classic Stroop task, in which an individual must ignore the written word (e.g., RED) and instead identify the color that the word is written in (e.g., blue; Stroop, 1935). Conflict monitoring is believed to be one key aspect of executive attention, along with computing task parameters, evaluating conflict, updating new or unlearned responses, regulating thoughts and emotions, and blocking habitual responding (Raz \& Buhle, 2006). Although a body of research supports both functional and neural separation of these networks, there is also evidence that it can be difficult to methodologically separate the attention networks, because they often operate in parallel (MacLeod et al., 2010). The majority of studies regarding attention performance and mindfulness practice have discussed improvements in terms of the three attention networks (Chan \& Woollacott, 2007; Chiesa, Calati, \& Serretti, 2011; Jha, Krompinger, \& Baime, 2007; Malinowski, 2013; Tang, Hölzel, \& Posner, 2015), and in order to evaluate the past literature consistently, we will also apply this approach. However, there are other frameworks within the broader attention literature, with the integrated competition hypothesis being another common explanation supported by neurocognitive findings (Desimone \& Duncan, 1995; Duncan, Humphreys, \& Ward, 1997). For a more indepth discussion of the ERP literature on attention, please refer to Luck (2014) or Picton et al. (2000).

In addition to task-specific attention improvements, we will give special consideration to past research and ERP markers of mind wandering. This is defined as the withdrawal of attention from task-relevant stimuli, which subsequently reduces the capacity of working memory. Mind wandering involves brain regions responsible for orienting, goal-directed behavior, and executive attention (Smallwood, Beach, Schooler, \& Handy, 2008). It has previously been linked to reductions in learning and task performance, as well as to clinical issues such as depression (Deng, Li, \& Tang, 2014; Mooneyham \& Schooler, 2013), and is therefore a process of particular interest to schools, given that mind wandering is known to occur most often in educational contexts (Unsworth, McMillan, Brewer, \& Spillers, 2012).

\section{ERP markers of attention and experimental paradigms for mindfulness research with adolescents}

The CNV The contingent negative variation represents attention activation, motor preparation, and a proactive response to suggested targets. It has a frontal/central distribution and has been linked to activation in the anterior cingulate cortex (ACC), PFC, and supplementary motor area (SMA) (Bares, Nestrasil, \& Rektor, 2007; Nagai et al., 2004). These brain regions have also been associated with increased activation during meditation in trained practitioners (Hölzel et al., 2007), which may signal that mindfulness practice benefits mental alertness (Posner, 2008). Tasks such as the Attention Network Test (ANT: Fan, McCandliss, Sommer, Raz, \& Posner, 2002) identify this orienting attention ability through measuring the response when spatial cues appear before an impending target. Jha, Krompinger, and Baime (2007) demonstrated that the orienting of attention is significantly improved in adults after an 8-week MBSR course.

The CNV might be a sensitive ERP component to detect possible facilitation of attention "priming"; for instance, Bostanov, Keune, Kotchoubey, and Hautzinger (2012) demonstrated that mindfulness practice can increase CNV negativity in depressed adult populations. Interestingly, Killikelly and Szucs (2013) showed that proactive response activation toward an imminent target, which correlated with morenegative CNV amplitudes, is reduced even in older adolescents, relative to young adults. Adolescents' suggested lack of orientation and proactive planning abilities, associated with 
a less-negative CNV (and less-efficient frontal lobe executive functioning), has potential consequences for risk-taking behaviors. This also means that testing paradigms aimed at manipulating the CNV will likely show poorer baseline functioning in adolescent participants than in adults. Nevertheless, this converging evidence on developmental CNV modulation in adolescents (Killikelly \& Szucs, 2013) - as well as the CNV's modifiability through mindfulness training in depressed populations (Bostanov et al., 2012), who also show dampened pretesting $\mathrm{CNV}$ responses-recommends this as a sensitive tool for understanding the underlying mechanisms of mindfulness-based change. More-negative CNV amplitudes could be expected after mindfulness training in adolescents, reflecting anticipatory mobilization of attentional resources.

The N200 Response inhibition is a strong contributor to performance in tasks of executive attention such as the Stroop (1935), go-no-go (Donders, 1969), and D2 (Brickenkamp, 1962) tasks, as well as the conflict subtask of the ANT, and can be monitored through the N200 (N2) negativity. Moore, Gruber, Derose, and Malinowski (2012) employed the Stroop task with mindfulness novices before and after an 8-week program (and at a 16-week follow-up), which involved an initial 2-h guided session and regular 10- to 15-min practices 5 days per week. No behavioral effects were found, but N2 amplitudes showed a significant Group $\times$ Time interaction (at occipito-parietal electrode clusters), which reflected morenegative amplitudes in the meditation group by follow-up. There was also a significant decrease in meditators' P3b amplitudes during incongruent trials. The authors suggested that the N2 amplitude changes indicated improvements in detection and inhibition, which subsequently led to fewer attentional resources being required for object recognition, reflected in less-positive P3b amplitudes. In other words, efficiently allocating cognitive resources to early detection left mental resources for maintaining task vigilance. In this context, the N2 can thus be interpreted as a direct index of response inhibition and can indicate the facilitation of improved orienting (attention shift) and alerting (vigilance) skills after mindfulness training. The nonsignificant group effect for performance highlights the idea that changes in the alerting system may be subtle, needing prolonged practice before enhanced attention leads to significantly more-accurate task performance. This favors neurocognitive methods of testing such as ERPs, which may identify early mechanisms of change. Ortner, Kilner, and Zelazo (2007) also reported that university students practicing mindfulness were better able to disengage from unpleasant stimuli, in comparison to those in a passive control or relaxation group. However, Ortner et al. observed no difference between groups when observing neutral or pleasant stimuli, suggesting that mindfulness practice does not uniformly disengage people from experience, but rather, prevents interference by negative stimuli. Future testing methods may correlate N2 and P3b amplitudes, as well as performance accuracy, using an oddball or "sustained attention to response" task (SART; Robertson, Manly, Andrade, Baddeley, \& Yiend, 1997).

With regard to adolescents, studies have shown that they have difficulty shifting attention away from emotive stimuli (e.g., Shackman et al., 2011). Being taught how to effectively reengage their attention through mindfulness could improve concentration levels at school, where social, emotional, and academic stressors are widespread and distracting. Bogels, Hoogstad, van Dun, de Schutter, and Restifo (2008) found that after an MBCT course, adolescents with externalizing disorders showed significant improvements on speed and accuracy measures of sustained attention (D2 test of attention; Brickenkamp, 1962), with further improvements by an 8week follow-up. Caution is needed when generalizing findings from clinical samples, but these results suggest that mindfulness can enhance sustained attention in this age group. In terms of typical development, Chapman, Woltering, Lamm, and Lewis (2010) mapped out N2 development in participants ranging from $8-17$ years old. They detected more-negative amplitudes and shorter latencies in adolescents, which suggests more-efficient and -mature processing, akin to adult levels. Therefore, similar to what has been reported in adult populations, more-negative N2 amplitudes could be expected after mindfulness training in clinical and nonclinical adolescent populations, reflecting enhanced patterns of automatic attention capture and inhibition.

The P300 The attentional-blink paradigm (Raymond, Shapiro, \& Arnell, 1992) is another measure of orienting and alerting performance. This measures an individual's ability to disengage from Target 1 (T1) and stay vigilant for detecting Target 2 (T2), both presented quickly (less than $500 \mathrm{~ms}$ apart) in a visual sequence of numbers and letters. In relation to mindfulness, Slagter et al. (2007) found significantly better T2 detection in participants after a 3-month mindfulness meditation retreat, as well as a selective reduction in T1-elicited P3b amplitudes on no-blink (i.e., successful T2 detection) trials. These results suggest that reducing attentional resources to T1 through meditation training increased an individual's chances of remaining vigilant and detecting $\mathrm{T} 2$. In terms of relating this to adolescents, Brumback et al. (2012) demonstrated that the maturity of the P300 amplitude and latency develops earlier in females - that is, reduced P300 positivities and shorter latencies. This suggests that male students may have more potential to improve attention performance after training, but also that baseline differences in mixed-gender groups should be controlled for. Research with adolescents specifically using the attentional-blink paradigm (Ray Li, Chen, Lin, \& Yang, 2005) has reported that impulsivity was associated with lower T2 detection. Improvements in adults (Slagter et al., 2007) would therefore suggest that mindfulness training might be particularly beneficial for adolescents with 
high impulsivity, with practice benefits being reflected in greater T2 detection and associated P3b amplitude decreases to T1.

The $\mathrm{P} 3 \mathrm{~b}$ reduction found after mindfulness training by Moore et al. (2012) during inhibition trials in the Stroop task reflects conflict monitoring and inhibitory performance in addition to alerting, discussed in the previous section. MBCT has also been shown to enhance executive control abilities in healthy adults (Chambers, Lo, \& Allen, 2008). Moore et al. (2012) showed no corresponding drop in task accuracy when P3b amplitudes decreased, suggesting a reduction in the amount of attentional resources required for executive control. However, Moore and Malinowski (2009) reported in a crosssectional study, with meditation-naive participants being compared to intermediate Buddhist students (who had at least completed the 6-week intensive course), that meditation students did perform significantly better in Stroop and D2 tasks. These improvements indicate better inhibitory control, cognitive flexibility, and quality of performance that might reflect the more intense nature of their meditation training. Other executive function tests use dual-task paradigms, such as the $n$-back paradigm (Watter, Geffen, \& Geffen, 2001) and task switching (Kieffaber \& Hetrick, 2005), which also modulate the P300. In dual-task paradigms, increases in task difficulty (including task switching) result in more-positive P300 amplitudes and prolonged latencies (Kramer, Wickens, \& Donchin, 1985). Palluel, Nougier, and Olivier (2010) identified 1415 years of age as the maturational turning point in dual-task performance, so that adults levels of performance should be anticipated in older adolescents unless affective stimuli are incorporated that prompt subcortical brain regions to interfere with executive functioning (Spear, 2013).

In contrast to the increased efficiency of attention resulting from mindfulness training, mind wandering is marked by a lack of efficient attention allocation. This can have a detrimental impact on education, in terms of both effective learning processes and academic performance. For example, during revision periods, an awareness of an individual's optimum attention span and an ability to catch themselves mind wandering could maximize both productivity and a sense of achievement. A person's susceptibility to mind wander can be measured using such simple, overlearned tasks as the SART (Robertson et al., 1997), in which behavioral performance correlates with self-reported mind wandering and $\mathrm{P} 3 \mathrm{~b}$ waveforms. Improvements in dual-task performance (which is essentially the internal environment that mind wandering creates) have been associated with activity in the ACC (Dreher \& Grafman, 2003), one of the key brain areas linked to mind wandering (Ros et al., 2013) and mindfulness practice (Hölzel et al., 2007). Less mind wandering correlates with greater P3b mean amplitudes to nontargets preceding a correctly inhibited response to target during the SART, suggesting more-consistent attention processing throughout (Smallwood et al., 2008). This contrasts with the reduced
$\mathrm{P} 3 \mathrm{~b}$ that is observed after mindfulness training in other attention-based tasks, thus highlighting the importance of context in neurocognitive theory and testing. Mind wandering has been shown to be reduced after brief mindfulness practice in adults (Mrazek, Smallwood, \& Schooler, 2012), and similar effects could be expected in adolescents, positively impacting on the effectiveness of their learning. Moreover, it would be very relevant to investigate whether temporary improvements such as those reported by Mrazek et al. could, with regular mindfulness training, translate into stable, trait-like reductions in mind wandering.

\section{Mindfulness training effects on emotion regulation}

Emotions are multifaceted phenomena involving the cognitive appraisal of a situation, physiological responses, emotional experience (feelings), and a tendency to respond (Scherer, 2000). The ability to manage emotions is described as emotion regulation (ER; Gross \& Thompson, 2007). Typically, emotions compete for attention with other cognitive processes that are demanded by a situation, and the prefrontal systems of attention control enable the inhibition, shifting of attention, and monitoring of emotions that underlie ER (Ochsner, Bunge, Gross, \& Gabrieli, 2002). This malleability by attention processes makes ER subject to maturation changes throughout development.

The links between attention control and ER have consequences for the adolescent population, since adolescents typically display poorer inhibition and more impulsive, risktaking behaviors. Specifically, Ernst, Pine, and Hardin's (2006) triadic model of motivated behavior illustrates how the adolescent reward-driven system (ventral striatum) may exert more control over adolescents' behavior than the harmavoidant (amygdala) and regulatory control (medial/ventral PFC) system that is still developing. In addition, reward regions of the brain are more strongly activated when young people take risks in the company of their peers (Steinberg, 2010), confirming the strong impact of peer pressure on this population. Gambling tasks such as that of Van Leijenhorst et al. (2010) exemplify that the adolescent ACC, which balances emotions with objective judgment, exerts less control over behavior than does the reward-oriented ventral striatum. This leads to riskier decisions based on the different developmental trajectories of these neural systems.

The connection between attention control and ER through the ACC is paramount to where mindfulness can influence ER strategies (Dywan, Mathewson, Choma, Rosenfeld, \& Segalowitz, 2008). It is possible that mindfulness practice could encourage connections between the relevant prefrontal structures in adolescents, stabilizing arousal and reducing harmful risk-taking, as has been advocated more broadly in support of mental training by Atkins, Bunting, Bolger, and 
Dougherty (2012). Relevant evidence for this has come from adult fMRI research; for example, Grant, Courtemanche, and Rainville (2011) found that proficient meditators display less activation in brain regions of executive functioning (lateral and medial PFC, ACC) while attending to pain. This may represent a selective reduction in unhelpful cognitive elaboration, translating into more effortless ER. Petter, McGrath, Chambers, and Dick (2014) reported similar behavioral findings, with mindfulness practice attenuating pain responses in typical adolescents. The influence of mindfulness practice on ER strategy is complex, however, and fMRI research has shown a shift in ER strategies with more extensive mindfulness experience. Taylor et al. (2011) reported that actively engaging in mindful meditation during negative picture displays caused bilateral deactivation of the amygdala for beginners, whereas long-term practitioners showed a deactivation in the left lateral PFC. Meditators may initially reappraise in order to modify maladaptive emotional responses, but progressively an all-accepting attitude leaves appraisal unnecessary (Teper, Segal, \& Inzlicht, 2013). Mapping the development of ER in adolescents will therefore need to take into account neurocognitive changes in relation to the length and quality of practice. The task designs and stimuli used will also influence the predictions made. During studies of pain tolerance, it is most adaptive to disengage from the incoming stimulus, and therefore less activation of the PFC may be recorded. Whereas, during an active ER task-for example, that of Creswell, Way, Eisenberger, and Lieberman (2007)_-individuals must first appraise stimuli for valence and then actively down-regulate the emotional response that this has upon the amygdala.

In the next section, we will review previous ERP research, outline specific testing paradigms, and suggest what neural markers sensitive to ER could be studied within the adolescent population.

\section{ERP markers of emotion processing and experimental paradigms for mindfulness research with adolescents}

The P300 In comparison to MRI research, the utilization of ERPs to interpret emotion regulation is still emerging. However, the applications of the P300 — described by Polich (2007) as having associations to executive attention, memory updating and retrieval (the $\mathrm{P} 3 \mathrm{~b}$ in particular), the dopaminergic reward system, and the PFC and ACC - all point to its relevance for ER. In particular, the $\mathrm{P} 3 \mathrm{~b}$ component has been linked to cognitive processing during emotion discrimination tasks, showing sensitivity to modulation by stimulus valence and intensity (Cavanagh \& Geisler, 2006), as well as arousal (Briggs \& Martin, 2009). The P300 has been shown to detect mindfulness effects in cognitive attention tasks such as the attentional-blink and the Stroop task with neutral stimuli (e.g., Moore et al., 2012; Slagter et al., 2007), indicating that the P300 may also prove a sensitive marker for changes to affective orientation linked to the efficiency of attention processing.

The ERN/Pe ER strategies associated with the ACC can be examined through the ERN ERP component, which is followed by the Pe - both elicited in trials in which participants make and review an error (van Veen \& Carter, 2002). There has been some discussion over the specific role of the ERN, since Endrass, Reuter, and Kathmann (2007) found no difference in ERN responses whether or not the error was noticed by the individual, whereas the Pe indicated more conscious error awareness. The ERN may be considered a neural correlate of conflict monitoring, signaling the need to increase cognitive control and modulate behavior (Botvinick, Braver, Barch, Carter, \& Cohen, 2001). A more negative ERN has been associated with general anxiety (Hajcak, McDonald, \& Simons, 2003) and negative mood (Hajcak, McDonald, \& Simons, 2004). The Pe component was unaffected during the anxiety study, and less positive Pe waveforms were reported in Hajcak et al. (2004) for a high-negative-affect group. The latter result was thought to indicate less salience for the individual when making an error. Interestingly, a cross-sectional study of nonmeditators following either a guided mindfulness practice $\mathrm{CD}$ or an educational talk demonstrated that the mindfulness induction also had the effect of reducing Pe mean amplitudes during error trials in a flanker task (Larson, Steffen, \& Primosch, 2013). This finding is particularly significant for older adolescents, who typically respond to errors with more-positive Pe amplitudes, signaling stronger affective responses than among either adults or children (Ladouceur et al., 2007). It could be expected that the kind, accepting attitude of mindfulness contributed to a less positive Pe coupled with an adequate response to error (ERN), in contrast to the apathetic Pe reduction seen in people with high negative affect. This is where sensitive self-report measures of error judgments in conjunction with ERP testing might be able to identify the mediating cause behind Pe modulation after mindfulness practice. The long-term effects of meditation on the ERN and Pe have been tested by Teper and Inzlicht (2013), with ERN negativity being positively correlated with meditation practice, without an amplitude increase in the Pe. Accurately responding to errors (ERN) without the upsurge in emotional response $(\mathrm{Pe})$ might allow adolescents to learn from their mistakes without self-punishment, a mechanism with clear links to reductions in risk-taking and self-harm that can otherwise result from hypercritical self-beliefs and negative affect (Klonsky, 2007).

The LPP Another promising component already tested in adults is the LPP, thought to index attention to emotional 
Table 1 ERP components of interest and corresponding research summary table

\begin{tabular}{|c|c|c|c|c|c|}
\hline $\begin{array}{l}\text { Event-Related } \\
\text { Potential }\end{array}$ & Definition & $\begin{array}{l}\text { Experimental } \\
\text { Paradigm / Task }\end{array}$ & Adolescent Patterns & Adult Patterns & $\begin{array}{l}\text { Predictions for } \\
\text { Adolescents Trained } \\
\text { in Mindfulness } \\
\text { Practices }\end{array}$ \\
\hline
\end{tabular}

\begin{tabular}{ccccc}
\hline $\begin{array}{c}\text { Contingent } \\
\text { negative }\end{array}$ & A slow-building negative & - Priming task with & - Killikelly and & Bostanov et al. \\
variation & waveform that emerges & informative and & Szucs (2013) proactive & $(2012)$ mindfulness \\
$(\mathrm{CNV})$ & in the period between & noninformative & response activation & practice leads to a \\
& $\begin{array}{l}\text { a warning and imperative } \\
\text { stimuli. It has a frontal/ }\end{array}$ & warning stimuli & toward an imminent & more negative CNV in \\
& $\begin{array}{l}\text { central distribution, } \\
\text { and signals preparatory }\end{array}$ & & target, which correlates & depressed adult \\
& motor activity, sensory & & with more negative & populations, who have \\
& anticipation, and the & & CNV amplitudes, is & dampened preintervention \\
& activation of attention & & dampened in older & CNV activity before \\
& & & adolescents compared & the intervention.
\end{tabular}

\begin{tabular}{|c|c|c|}
\hline Visual N2 & $\begin{array}{l}\text { The visual N2 is a negative } \\
\text { deflection with frontal/ } \\
\text { central distribution, } \\
\text { and it signals task-specific } \\
\text { inhibition (Falkenstein } \\
\text { et al., 1999) and } \\
\text { conflict monitoring } \\
\text { (Ladouceur et al., 2007). } \\
\text { The N2 can also be detected } \\
\text { at occipital sites } \\
\text { (Fabiani et al., 2000). }\end{array}$ & $\begin{array}{l}\text { - Inhibition or detection } \\
\text { task } \\
\text { - Stroop test } \\
\quad \text { (Stroop, 1935) } \\
\text { - Go, no-go task } \\
\text { (Donders, 1969) } \\
\text { - D2 (Brickenkamp, 1962) } \\
\text { - Attention Network Test, } \\
\text { conflict-monitoring } \\
\text { task (Fan et al., 2002) } \\
\text { - Odd-ball paradigms }\end{array}$ \\
\hline
\end{tabular}

- Chapman et al. (2010)
mapped out $\mathrm{N} 2$
development, detecting
more negative amplitudes
and shorter latencies in
adolescents compared
to children. This suggests
more efficient and mature
processing in older
adolescents, comparable
to adult levels.

- Moore et al (2012) more negative $\mathrm{N} 2$ response after mindfulness training in Stroop task. This modulation has also been linked to reduced P3 positivity, suggesting that stronger inhibition reduces the cost of attentional resources on goal-irrelevant stimuli.

\footnotetext{
P300

*Specific

interest in $P 3 b$ sub-component
}

\footnotetext{
- Focused attention and executive tasks

- Dual-task paradigms e.g. $n$-back (Watter et al., 2001) and task switching (Kieffaber \& Hetrick, 2005)

- Attentional-blink paradigm (Raymond et al., 1992)

- Stroop (Stroop, 1935)

- Odd-ball paradigm

- SART (Robertson et al., 1997)
}

- Brumback et al. (2012)
the developmental
maturity of P300
amplitude and latency
responses during a visual
odd-ball task develops
sooner in females
(i.e. shorter P300 latency
and less positive P300
waveforms). This suggests
that males have a slower
developmental trajectory,
and executive attention in
particular is still
developing well into
older adolescence.

- Slagter et al.

(2007)-improved T2

detection after mindfulness training in the attentional-blink task. Performance was associated with reduced T1-elicited P3b amplitude over time, suggesting more efficient orientating and alerting.

- Moore et al. (2012)—P3b amplitude reduction during Stroop task on incongruous targets after mindfulness training. This suggests a reduced cost on attention resources for target inhibition.
- The CNV can detect

facilitation of anticipatory attention processes after mindfulness interventions, as indicated by converging evidence on developmental CNV modulation in adolescents (Killikelly \& Szucs, 2013) and its modifiability through mindfulness training in depressed populations (Bostanov et al., 2012).

- More negative CNV amplitudes could be expected after training.

- More negative N2 amplitudes could be expected after mindfulness training in adolescent populations, reflecting more mature patterns of inhibition (Chapman et al., 2010).

- N2 amplitudes should correlate with P3 responses and performance accuracy in odd-ball or SART (Robertson et al., 1997) paradigms, given that increased N2 may result in a reduction of $\mathrm{P} 3 \mathrm{~b}$ amplitude while maintaining or increasing task accuracy and vigilance.

- Possible links between N2 modulation and well-being since better inhibition has partially mediated increased well-being in adults (Sauer, Walach, \& Kohls, 2011).

- Attentional-blink paradigm is a possible ERP marker to map the development of orientating and alerting performance in adolescents, and could be particularly useful in relation to high impulsivity

(Ray Li et al., 2005), reflected in improvements to $\mathrm{T} 2$ detection and associated decreases in P3b to T1.

- Palluel et al. (2010) 14-15 years is the turning point for dual-task performance. Thus, adult levels of performance could be anticipated in older adolescents, reflected in reduced P300 amplitudes in 
Table 1 (continued)

\begin{tabular}{|c|c|c|c|c|c|}
\hline $\begin{array}{l}\text { Event-Related } \\
\text { Potential }\end{array}$ & Definition & $\begin{array}{l}\text { Experimental } \\
\text { Paradigm / Task }\end{array}$ & Adolescent Patterns & Adult Patterns & $\begin{array}{l}\text { Predictions for } \\
\text { Adolescents Trained } \\
\text { in Mindfulness } \\
\text { Practices }\end{array}$ \\
\hline
\end{tabular}

\begin{tabular}{|c|c|c|c|c|c|}
\hline & & & & $\begin{array}{l}\text { - Smallwood et al. (2008) } \\
\text { less mind wandering } \\
\text { correlates with greater } \\
\text { P3b mean amplitudes } \\
\text { during the SART, } \\
\text { suggesting more consistent } \\
\text { attention processing. } \\
\text { Mind wandering has also } \\
\text { been shown to reduce } \\
\text { after mindfulness practice } \\
\text { (Mrazek et al., 2012) } \\
\text { suggesting that P3b } \\
\text { amplitudes would be a } \\
\text { useful psycho-physiological } \\
\text { marker of mind wandering } \\
\text { reduction after mindfulness } \\
\text { training. }\end{array}$ & $\begin{array}{l}\text { Stroop or task-switching } \\
\text { paradigms. } \\
\text { - Where postintervention } \\
\text { P3b amplitude is reduced, } \\
\text { a corresponding increase } \\
\text { is anticipated for early } \\
\text { components-e.g., CNV } \\
\text { or N2 - signaling better } \\
\text { preparation, detection, } \\
\text { or inhibition. } \\
\text { - Similar mind wandering } \\
\text { effects could be anticipated } \\
\text { in adolescents as in adults } \\
\text { (Mrazek et al., 2012; } \\
\text { Smallwood et al., 2008), } \\
\text { impacting learning and } \\
\text { academic performance. }\end{array}$ \\
\hline $\begin{array}{l}\text { Error-related } \\
\text { negativity } \\
(\mathrm{ERN}) \text { and error } \\
\text { positivity }(\mathrm{Pe})\end{array}$ & $\begin{array}{l}\text { ERN is a negative deflection } \\
\text { over fronto-central sites, } \\
\text { signifying attention to } \\
\text { an error deviating from } \\
\text { goal-directed behavior } \\
\text { (Falkenstein et al., 1991). } \\
\text { This is followed by error } \\
\text { Positivity (Pe), which is } \\
\text { sensitive to the subsequent } \\
\text { appraisal of error severity } \\
\text { (Overbeek et al., 2005). }\end{array}$ & $\begin{array}{l}\text { - Any task requiring accuracy, } \\
\text { with higher likelihood of } \\
\text { errors that can be detected } \\
\text { or alerted to } \\
\text { - Stroop task (Stroop, 1935) } \\
\text { - Flanker task } \\
\text { (Eriksen \& Eriksen, 1974) }\end{array}$ & $\begin{array}{l}\text { - Ladouceur et al. (2007) } \\
\text { reported that Pe amplitudes } \\
\text { showed a developmental } \\
\text { peak in older adolescents, } \\
\text { responding to errors with } \\
\text { more positive amplitudes } \\
\text { than either young } \\
\text { adolescent or adult } \\
\text { participants. }\end{array}$ & $\begin{array}{l}\text { - Long-term effects of meditation } \\
\text { on ERN and Pe have been } \\
\text { tested by Teper and Inzlicht } \\
\text { (2013). ERN negativity } \\
\text { positively correlated with } \\
\text { meditation practice, and } \\
\text { emotional acceptance, } \\
\text { without an amplitude } \\
\text { increase in Pe, following } \\
\text { Stroop task errors. } \\
\text { - Larson et al. (2013), a } \\
\text { cross-sectional study } \\
\text { of nonmeditators } \\
\text { following either a } \\
\text { guided mindfulness } \\
\text { CD or educational talk. } \\
\text { Mindfulness induction } \\
\text { corresponded with reduced } \\
\text { Pe mean amplitudes after } \\
\text { errors on the Eriksen } \\
\text { flanker task. }\end{array}$ & $\begin{array}{l}\text { - Accurately identifying errors } \\
\text { (more negative ERN) } \\
\text { without the upsurge in } \\
\text { emotional response } \\
\text { (no change or less } \\
\text { positive Pe amplitude), } \\
\text { might allow adolescents } \\
\text { to learn from their mistakes } \\
\text { without self-punishment. } \\
\text { This mechanism could } \\
\text { have links to reducing } \\
\text { hypercritical self-judgment } \\
\text { that can otherwise result in } \\
\text { extreme risk-taking } \\
\text { and self-harm } \\
\text { (Klonsky, 2007). }\end{array}$ \\
\hline $\begin{array}{l}\text { Late positive } \\
\text { potential (LPP) }\end{array}$ & $\begin{array}{l}\text { A slow-building positive } \\
\text { waveform, with a } \\
\text { central/posterior } \\
\text { distribution. Considered } \\
\text { to be a neural marker } \\
\text { of emotional arousal, } \\
\text { reflecting preferential } \\
\text { processing and encoding } \\
\text { of motivationally } \\
\text { relevant stimuli } \\
\text { (Brown et al., 2013). }\end{array}$ & $\begin{array}{l}\text { - Passive viewing or hearing } \\
\text { of affective stimuli } \\
\text { - Affect labeling task } \\
\text { - Affect induction / regulation } \\
\text { tasks (e.g. Hajcak \& } \\
\text { Nieuwenhuis, 2006) }\end{array}$ & $\begin{array}{l}\text { - LPP response modulation } \\
\text { does not reach adult } \\
\text { levels until late adolescence } \\
\text { (Zhang et al., 2012). } \\
\text { Developmental increases } \\
\text { indicate more adaptive } \\
\text { attention processing. } \\
\text { - Zhang et al. (2013), peak } \\
\text { emotional ratings of pictures } \\
\text { and LPP amplitudes } \\
\text { reported in young } \\
\text { adolescents, corresponding } \\
\text { to the undeveloped } \\
\text { nature of their ER abilities. }\end{array}$ & $\begin{array}{l}\text { - Brown et al. (2013) found } \\
\text { a strong inverse correlation } \\
\text { between dispositional } \\
\text { mindfulness and the LPP } \\
\text { amplitude elicited by } \\
\text { high-arousal, unpleasant } \\
\text { stimuli in a passive } \\
\text { International Affective } \\
\text { Picture System (IAPS) } \\
\text { picture-viewing task. }\end{array}$ & $\begin{array}{l}\text { - Mindfulness training may } \\
\text { impact on the strength of } \\
\text { emotional responses, } \\
\text { reflected in LPP amplitude } \\
\text { reduction (possibly linked } \\
\text { to less arousal and better } \\
\text { emotion regulation), in the } \\
\text { young adolescent } \\
\text { population (Zhang et al., } \\
\text { 2013). }\end{array}$ \\
\hline $\begin{array}{l}\text { Late positive } \\
\text { complex (LPC) }\end{array}$ & $\begin{array}{l}\text { Positive, broad-peaking } \\
\text { waveform with a parietal } \\
\text { distribution. It is associated } \\
\text { with deep processing } \\
\text { (Rellecke et al., 2012), } \\
\text { memory recall } \\
\text { (Schaefer et al., 2011), } \\
\text { and affective rumination } \\
\text { (Sitges et al., 2007). }\end{array}$ & $\begin{array}{l}\text { - Passive viewing or } \\
\text { hearing affective stimuli } \\
\text { - Negative emotion "priming" } \\
\text { tasks, combining CNV and } \\
\text { LPC neural markers to map } \\
\text { regulation through initial } \\
\text { attention deployment (CNV), } \\
\text { followed by reduction } \\
\text { in rumination (LPC) }\end{array}$ & $\begin{array}{l}\text { - Marks et al. (2010) found } \\
\text { that higher levels of } \\
\text { rumination exacerbate } \\
\text { the relationship between } \\
\text { self-reported life hassles } \\
\text { and depression and } \\
\text { anxiety, whereas higher } \\
\text { dispositional mindfulness } \\
\text { can alleviate these }\end{array}$ & $\begin{array}{l}\text { - Rellecke et al.'s (2012) LPC } \\
\text { mean amplitude increases } \\
\text { were induced only when } \\
\text { participants intentionally } \\
\text { focused attention on affective } \\
\text { facial stimuli, indicating } \\
\text { individual's voluntary } \\
\text { control over higher } \\
\text { cognitive emotion }\end{array}$ & $\begin{array}{l}\text { - Initial correlational studies } \\
\text { measuring dispositional } \\
\text { mindfulness, trait rumination } \\
\text { and the LPC in adolescents } \\
\text { could provide useful insights; } \\
\text { increased rumination and } \\
\text { decreased mindfulness } \\
\text { should be linked to less } \\
\text { positive LPC amplitudes. }\end{array}$ \\
\hline
\end{tabular}


Table 1 (continued)

\begin{tabular}{|c|c|c|c|c|c|}
\hline $\begin{array}{l}\text { Event-Related } \\
\text { Potential }\end{array}$ & Definition & $\begin{array}{l}\text { Experimental } \\
\text { Paradigm / Task }\end{array}$ & Adolescent Patterns & Adult Patterns & $\begin{array}{l}\text { Predictions for } \\
\text { Adolescents Trained } \\
\text { in Mindfulness } \\
\text { Practices }\end{array}$ \\
\hline & & - Affect labeling task & same links. & processing. & $\begin{array}{l}\text { - Training adolescents in } \\
\text { mindfulness techniques } \\
\text { may protect them against } \\
\text { the damaging effects of } \\
\text { rumination on well-being } \\
\text { (Marks et al., 2010), } \\
\text { reflected in reduced LPC. } \\
\text { - Future studies could test } \\
\text { the process of change } \\
\text { in ER using LPC and } \\
\text { CNV ERP neural } \\
\text { markers. }\end{array}$ \\
\hline
\end{tabular}

stimuli. More LPP positivity is typically found to unpleasant, high-arousal stimuli (Brown et al., 2013) interpreted as reflecting the "negativity bias" of rapid amygdala activation and processing to threatening stimuli (LeDoux, 1995). Importantly, "top-down" projections from the PFC can influence LPP responses; for example, Hajcak and Nieuwenhuis (2006) reported amplitude reduction when unpleasant stimuli were deliberately reappraised more positively. This has been aligned with reductions in amygdala activation and increases in PFC responses seen after mindfulness training (Goldin \& Gross, 2010; Goldin, Ziv, Jazaieri, Hahn, \& Gross, 2013). Indeed, Brown et al. (2013) found a strong inverse correlation between dispositional mindfulness and the LPP amplitude elicited by high-arousal unpleasant stimuli in a passive picture-viewing task. No research linking the LPP to mindfulness training has been conducted with adolescents, but it is known that LPP responses do not reach adult levels of modulation until late adolescence (Zhang et al., 2012). Peak emotional ratings of pictures and LPP amplitudes have been reported in young adolescents (Zhang et al., 2013), corresponding to the undeveloped nature of their ER abilities. It would be interesting to investigate whether mindfulness training can impact on the strength of emotional responses reflected in the LPP modulation in a young adolescent population.

The CNV combined with the LPC The last waveform of interest is the CNV, in conjunction with a late target stimulus-related ERP component, the LPC. During a negative-emotion "priming" task, more-negative CNV amplitudes to the warning stimulus followed by a reduced LPC could represent early preparation (Walter et al., 1964), followed by a reduction of secondary processing and rumination regarding that stimulus (Sitges et al., 2007). This ERP pattern could be used to map improvements in participants' regulation through initial attention deployment and preparation (CNV), as has been seen in mindfulness research with depressed populations (Bostanov et al., 2012), followed by a withdrawal of appraisal and a reduction in rumination (LPC). Little research has looked into the potential of the LPC to signal adaptive ER, but tasks with affective stimuli manipulating an increase or reduction in rumination seem most suitable to test possible modulations of the LPC by mindfulness practice, with more-positive LPC amplitudes reflecting less adaptive (more ruminative) processing. Support for this approach has come from Rellecke et al. (2012), who observed that LPC amplitudes increased when participants willfully focused their attention on affective facial stimuli, indicating individuals' voluntary control over higher-cognitive emotion processing. Interestingly, a dispositional study of Australian adolescents reported that higher levels of rumination exacerbate the relationship between self-reported life hassles and depression and anxiety, whereas higher mindfulness levels alleviated these same links (Marks, Sobanski, \& Hine, 2010). Training young people in mindfulness techniques may therefore work to protect them against the damaging effects of rumination on wellbeing while dealing with everyday stressors. Potential future studies could examine whether such effects are detectable when measuring LPC and CNV ERP neural markers.

\section{Conclusions}

We have argued that the neurodevelopmental perspective belongs to the frontiers of future research on mindfulness in adolescents, and the ERP methodology could prove particularly useful in this context. What is needed is an integrative approach in which (a) mindfulness programs are informed by neurodevelopmental trajectories and allow for adaptation in order to target developmentally salient challenges, such as disengaging from affectively salient stimuli or the lessening of peer pressure influences in adolescents; and (b) evaluations of mindfulness curricula focus on the aspects of 
neurocognitive function targeted by that particular mindfulness program. For example, an investigation of morenegative N2 amplitudes in response to interfering stimuli after mindfulness training, which would reflect more efficient disengagement that is linked to the development of an accepting attitude. Experiments utilizing ERPs can be particularly helpful here because of their functional sensitivity to shifts in attention control, the low cost of EEG equipment, and its portability, which enables more naturalistic experimental testing in schools, beyond the restrictive lab environment. To enable broader utilization of ERPs in developmental intervention studies on mindfulness, more basic research on reliable ERP markers is needed. This is particularly relevant to investigations of ER, since studies in both adults and children have been scarce. The initial research points to modulations of the LPP by emotion regulation strategies (Hajcak \& Nieuwenhuis, 2006) and by trait mindfulness (Brown et al., 2013), but in the absence of longitudinal and developmental studies it is not clear how mindfulness as a unique ER strategy could modify the LPP component. It is also possible that with more mindfulness practice, the mindful ER strategy would lead to the modulation of ERP components (such as the P300) peaking earlier than the LPP. This would be due to shifts in more automatic responding to emotionally salient stimuli, as was suggested by adult fMRI research with beginners and long-term meditation practitioners (Taylor et al., 2011). Given the paucity of available research on ER with ERPs, measures of attention control and efficiency may be the most prudent outcomes to begin researching developmentally, since the ERP findings of mindfulness training in adults allow for more-confident predictions - that is, a more negative N2 (Moore et al., 2012) and less P300 positivity (Slagter et al., 2007).

In addition, researchers and mindfulness trainers need to work together when attuning mindfulness programs for developmentally and population- (e.g., gender-) specific features, such as adjustments to the frequency and length of home practices. Collaborations are needed in the evaluation process, to include converging assessments from self-reports and neurocognitive measures in combination with behavioral assessments from teachers and parents (where appropriate). And ideally, such research would inform education policy, focusing on investigating changes in variables that are high on school policy agendas, such as metacognition, attention, and well-being. An example would be to study changes in adolescent mind wandering after mindfulness training, which would investigate shifts in self-reported mind wandering together with modifications in target detection accuracy and P3b amplitudes reflecting attention efficiency. These findings could be linked to well-being assessments and behavioral reports of pupils' selfregulation from teachers, as well as academic attainment records. Neurocognitive evidence would be key in this multidisciplinary approach, since only neurodevelopmental experimental paradigms can address focused questions regarding the endogenous trajectories of change in emotion regulation and attention within school-based mindfulness programs. In this way, neurocognitive research can provide pivotal evidence for education policy makers. A similar approach has been applied by the Neville lab to assess the neurocognitive basis of poor attention performance in children from lower socio-economic status (SES) backgrounds. These findings have guided focused interventions, which enhanced attention abilities in children from lower SES families (Stevens, Fanning, Coch, Sanders, \& Neville, 2008).

To conclude, it is our hope that the considerations and research suggestions outlined in this article will inspire more researchers to adopt an integrative neurodevelopmental approach to the study of mindfulness, particularly using the ERP methodology. This will in turn boost our understanding of underlying mechanisms and help us fully harness the potential of mindfulness practice to improve well-being and support the neurocognitive development of adolescents.

Author note This work was supported by the ESRC Welsh DTC (Grant Number ES/J500197/1), Bangor School of Psychology, and the Centre for Mindfulness Research and Practice.

Open Access This article is distributed under the terms of the Creative Commons Attribution 4.0 International License (http:// creativecommons.org/licenses/by/4.0/), which permits unrestricted use, distribution, and reproduction in any medium, provided you give appropriate credit to the original author(s) and the source, provide a link to the Creative Commons license, and indicate if changes were made.

\section{References}

Atkins, S. M., Bunting, M. F., Bolger, D. J., \& Dougherty, M. R. (2012). Training the adolescent brain: Neural plasticity and the acquisition of cognitive abilities. In V. F. Reyna, S. B. Chapman, M. R. Dougherty, \& J. Confrey (Eds.), The adolescent brain: Learning, reasoning, and decision making (pp. 211-242). Washington, DC: American Psychological Association.

Baer, R. A. (2003). Mindfulness training as a clinical intervention: A conceptual and empirical review. Clinical Psychology: Science and Practice, 10, 125-143.

Bares, M., Nestrasil, I., \& Rektor, I. (2007). The effect of response type (motor output versus mental counting) on the intracerebral distribution of the slow cortical potentials in an externally cued (CNV) paradigm. Brain Research Bulletin, 71, 428-435.

Biegel, G. M. (2009). The stress reduction workbook for teens: Mindfulness skills to help you deal with stress. Oakland, CA: New Harbinger.

Biegel, G. M., Brown, K. W., Shapiro, S. L., \& Schubert, C. M. (2009). Mindfulness-based stress reduction for the treatment of adolescent psychiatric outpatients: A randomised clinical trial. Journal of Consulting and Clinical Psychology, 77, 855-866.

Bishop, S. R., Lau, M., Shapiro, S., Carlson, L., Anderson, N. D., Carmody, J., ... Devins, G. (2004). Mindfulness: A proposed operational definition. Clinical Psychology: Science and Practice, 11, 230-241.

Black, D. S., Milam, J., \& Sussman, S. (2009). Sitting-meditation interventions among youth: A review of treatment efficacy. Pediatrics, 124, 532-541. 
Bogels, S., Hoogstad, B., van Dun, L., de Schutter, S., \& Restifo, K. (2008). Mindfulness training for adolescents with externalising disorders and their parents. Behaviour and Cognitive Psychotherapy, 36, 193-209.

Bostanov, V., Keune, P. M., Kotchoubey, B., \& Hautzinger, M. (2012). Event-related brain potentials reflect increased concentration ability after mindfulness-based cognitive therapy for depression: A randomized clinical trial. Psychiatry Research, 199, 174-180.

Botvinick, M. M., Braver, T. S., Barch, D. M., Carter, C. S., \& Cohen, J. D. (2001). Conflict monitoring and cognitive control. Psychological Review, 108, 624-652. doi:10.1037/0033-295X.108.3.624

Bradshaw, C. P., Goldweber, A., Fishbein, D., \& Greenberg, M. T. (2012). Infusing developmental neuroscience into school-based preventative interventions: Implications and future directions. Journal of Adolescent Health, 51, S41-S47.

Brickenkamp, R. (1962). Aufmerksamkeits-Belastungs-Test (Test D2). Göttingen, Germany: Hogrefe.

Briggs, K. E., \& Martin, F. H. (2009). Affective picture processing and motivational relevance: Arousal and valence effects on ERPs in an oddball task. International Journal of Psychophysiology, 72, 299 306.

Broderick, P. C. (2013). Learning to breathe: A mindfulness curriculum for adolescents to cultivate emotion regulation, attention, and performance. Oakland, CA: New Harbinger.

Broderick, P. C., \& Metz, S. (2009). Learning to BREATHE: A pilot trial of a mindfulness curriculum for adolescents. Advances in School Mental Health Promotion, 2, 35-46.

Brown, K. W., Goodman, R. J., \& Inzlicht, M. (2013). Dispositional mindfulness and the attenuation of neural responses to emotional stimuli. Social Cognitive and Affective Neuroscience, 1, 93-99.

Brown, K. W., Ryan, R. M., \& Creswell, J. D. (2007). Mindfulness: Theoretical foundations and evidence for its salutary effects. Psychological Inquiry, 18, 211-237.

Brumback, T. Y., Arbel, Y., Donchin, E., \& Goldman, M. S. (2012). Efficiency of responding to unexpected information varies with sex, age, and pubertal development in early adolescence. Psychophysiology, 49, 1330-1339.

Burke, C. A. (2010). Mindfulness-based approaches with children and adolescents: A preliminary review of current research in an emergent field. Journal of Child and Family Studies, 19, 133-144.

Cavanagh, J., \& Geisler, M. W. (2006). Mood effects on the ERP processing of emotional intensity in faces: A P3 investigation with depressed students. International Journal of Psychophysiology, 60, 27-33.

Centre for Mindfulness Research and Practice (2014). Mindfulness in education. Retrieved February 27, 2014, from www.bangor.ac.uk/ mindfulness/education.php.en

Chambers, R., Lo, B. C. Y., \& Allen, N. B. (2008). The impact of intensive mindfulness training on attentional control, cognitive style, and affect. Cognitive Therapy and Research, 32, 303-322.

Chan, D., \& Woollacott, M. (2007). Effects of level of meditation experience on attentional focus: Is the efficiency of executive or orientation networks improved? Journal of Alternative and Complementary Medicine, 13, 651-658.

Chapman, H. A., Woltering, S., Lamm, C., \& Lewis, M. D. (2010). Hearts and minds: Coordination of neurocognitive and cardiovascular regulation in children and adolescents. Biological Psychology, 84, 296 303

Chiesa, A., Calati, R., \& Serretti, A. (2011). Does mindfulness training improve cognitive abilities? A systematic review of neuropsychological findings. Clinical Psychology Review, 31, 449-464.

Creswell, J. D., Way, B. M., Eisenberger, N. I., \& Lieberman, M. F. (2007). Neural correlates of dispositional mindfulness during affect labeling. Psychosomatic Medicine, 69, 560-565.

Davidson, R. J., Dunne, J., Eccles, J. S., Engle, A., Greenberg, M., Jennings, P., ... Vago, D. The Mind and Life Education Research
Network: MLERN (2012). Contemplative practices and mental training: Prospects for American education. Child Development Perspectives, 6, 146-153.

Deng, Y. Q., Li, S., \& Tang, Y. Y. (2014). The relationship between wandering mind, depression and mindfulness. Mindfulness, 5, 124-128.

Desimone, R., \& Duncan, J. (1995). Neural mechanisms of selective visual attention. Annual Review of Neuroscience, 18, 193-222. doi:10.1146/annurev.ne.18.030195.001205

Desrosiers, A., Vine, V., Curtiss, J., \& Klemanski, D. H. (2014). Observing nonreactively: A conditional process model linking mindfulness facets, cognitive emotion regulation strategies, and depression and anxiety symptoms. Journal of Affective Disorders, 165, $31-37$.

Dewulf, D. (2009). Mindfulness voor jongeren. Tielt, Belgium: Lannoo.

Donders, F. C. (1969). On the speed of mental processes. Acta Psychologica, 30, 412-431. doi:10.1016/0001-6918(69)90065-1

Dorjee, D., \& Bowers, J. S. (2012). What can fMRI tell us about the locus of learning? Cortex, 48, 509-514.

Dreher, J. C., \& Grafman, J. (2003). Dissociating the roles of the rostral anterior cingulate and the lateral prefrontal cortices in performing two tasks simultaneously or successively. Cerebral Cortex, 13, 329339.

Duncan, J., Humphreys, G. W., \& Ward, R. (1997). Competitive brain activity in visual attention. Current Opinion in Neurobiology, 7 , 255-261.

Dweck, C. (2008). Can personality be changed? The role of beliefs in personality and change. Current Directions in Psychological Science, 17, 391-394.

Dywan, J., Mathewson, K. J., Choma, B. L., Rosenfeld, B., \& Segalowitz, S. J. (2008). Autonomic and electrophysiological correlates of emotional intensity in older and younger adults. Psychophysiology, 45, 389-397.

Eberth, J., \& Sedlmeier, P. (2012). The effects of mindfulness meditation: A meta-analysis. Mindfulness, 3, 174-189.

Endrass, T., Reuter, B., \& Kathmann, N. (2007). ERP correlates of conscious error recognition: Aware and unaware errors in an antisaccade task. European Journal of Neuroscience, 26, 1714-1720.

Eriksen, B. A., \& Eriksen, C. W. (1974). Effects of noise letters upon the identification of a target letter in a nonsearch task. Perception \& Psychophysics, 16, 143-149. doi:10.3758/BF03203267

Ernst, M., Pine, D. S., \& Hardin, M. (2006). Triadic model of the neurobiology of motivated behaviour in adolescence. Psychological Medicine, 36, 299-312.

Fabiani, M., Gratton, G., \& Coles, M. G. H. (2000). Event-related brain potentials: Methods, theory, and applications. In J. T. Cacioppo, L. G. Tassinary, \& G. G. Bernston (Eds.), Handbook of psychophysiology (2nd ed., pp. 53-84). New York, NY: Cambridge University Press.

Falkenstein, M., Hohnsbein, J., Hoormann, J., \& Blanke, L. (1991). Effects of cross-modal divided attention on late ERP components. Error processing in choice reaction tasks. Electroencephalography and Clinical Neurophysiology, 78, 447-455.

Falkenstein, M., Hoormann, J., \& Hohnsbein, J. (1999). ERP components in Go/Nogo tasks and their relation to inhibition. Acta Psychologica, 101, 267-291.

Fan, J., McCandliss, B. D., Sommer, T., Raz, A., \& Posner, M. I. (2002). Testing the efficiency and independence of attentional networks. Journal of Cognitive Neuroscience, 14, 340-347. doi:10.1162/ 089892902317361886

Flook, L., Smalley, S. L., Kitil, M. J., Galla, B. M., Kaiser-Greenland, S., Locke, J., ... Kasari, C. (2010). Effects of mindful awareness practices on executive functions in elementary school children. Journal of Applied School Psychology, 26, 70-95.

Foret, M. M., Scult, M., Wilcher, M., Chudnofsky, R., Malloy, L., Hasheminejad, N., \& Park, E. R. (2012). Integrating a relaxation 
response-based curriculum into a public high school in Massachusetts. Journal of Adolescence, 35, 325-332.

Gardner, M., \& Steinberg, L. (2005). Peer influence on risk taking, risk preference, and risky decision making in adolescence and adulthood: An experimental study. Developmental Psychology, 41, 625.

Goldin, P. R., \& Gross, J. J. (2010). Effects of mindfulness-based stress reduction (MBSR) on emotion regulation in social anxiety disorder. Emotion, 10, 83-91.

Goldin, P., Ziv, M., Jazaieri, H., Hahn, K., \& Gross, J. J. (2013). MBSR vs. aerobic exercise in social anxiety: fMRI of emotion regulation of negative self-beliefs. Social Cognitive and Affective Neuroscience, 8, 65-72. doi:10.1093/scan/nss054

Gould, L. F., Dariotis, J. K., Mendelson, T., \& Greenberg, M. (2012). A school-based mindfulness intervention for urban youth: Exploring moderators of intervention effects. Journal of Community Psychology, 40, 968-982.

Grant, J. A., Courtemanche, J., \& Rainville, P. (2011). A non-elaborative mental stance and decoupling of executive and pain-related cortices predicts low pain sensitivity in Zen meditators. Pain, 152, 150-156.

Greenberg, M. T., \& Harris, A. R. (2012). Nurturing mindfulness in children and youth: Current state of research. Child Development Perspectives, 6, 161-166.

Greenberg, M. T., \& Rhoades, B. L. (2008). State of science review: Self regulation and executive function - What can teachers and schools do? London, UK: Office of Science and Innovation, Foresight Project: Mental Capital and Mental Wellbeing.

Gross, J. J., \& Thompson, R. A. (2007). Emotion regulation: Conceptual foundations. In J. J. Gross (Ed.), Handbook of emotion regulation (pp. 3-24). New York, NY: Guilford Press.

Grossman, P., Niemann, L., Schmidt, S., \& Walach, H. (2004). Mindfulness-based stress reduction and health benefits: A metaanalysis. Journal of Psychosomatic Research, 57, 35-43.

Hajcak, G., McDonald, N., \& Simons, R. F. (2003). Anxiety and errorrelated brain activity. Biological Psychology, 64, 77-90.

Hajcak, G., McDonald, N., \& Simons, R. F. (2004). Error-related psychophysiology and negative affect. Brain and Cognition, 56, 189197. doi:10.1016/j.bandc.2003.11.001

Hajcak, G., \& Nieuwenhuis, S. (2006). Reappraisal modulates the electrocortical response to unpleasant pictures. Cognitive, Affective, \& Behavioral Neuroscience, 6, 291-297. doi:10.3758/ CABN.6.4.291

Hofmann, S. G., Sawyer, A. T., Witt, A. A., \& Oh, D. (2010). The effect of mindfulness-based therapy on anxiety and depression: A metaanalytic review. Journal of Consulting and Clinical Psychology, 78, 169-183. doi:10.1037/a0018555

Hölzel, B. K., Lazar, S. W., Gard, T., Schuman-Olivier, Z., Vago, D. R., \& Ott, U. (2011). How does mindfulness meditation work? Proposing mechanisms of action from a conceptual and neural perspective. Perspectives on Psychological Science, 6, 537-559.

Hölzel, B. K., Ott, U., Hempel, H., Hackl, A., Wolf, K., Stark, R., \& Vaitl, D. (2007). Differential engagement of anterior cingulate and adjacent medial frontal cortex in adept meditators and non-meditators. Neuroscience Letters, 421, 16-21.

Huppert, F. A., \& Johnson, D. M. (2010). A controlled trial of mindfulness training in schools: The importance of practice for an impact on well-being. Journal of Positive Psychology, 5, 264-274.

Jha, A. P., Krompinger, J., \& Baime, M. J. (2007). Mindfulness training modifies subsystems of attention. Cognitive, Affective, \& Behavioral Neuroscience, 7, 109-119. doi:10.3758/CABN.7.2.109

Justo, C. F. (2009). Efectos de un programa de meditación sobre los niveles de creatividad verbal de un grupo de alumnos/as de Bachillerato. Revista Suma Psicológica, 16, 113-120.

Kabat-Zinn, J. (1990). Full catastrophe living: Using the wisdom of your body and mind to face stress, pain, and illness. New York, NY: Delacorte.
Kabat-Zinn, J. (1994). Wherever you go, there you are: Mindfulness meditation in everyday life. New York, NY: Hyperion.

Kaplan, D. S., Liu, R. X., \& Kaplan, H. B. (2005). School related stress in early adolescence and academic performance three years later: The conditional influence of self expectations. Social Psychology of Education, 8, 3-17.

Kieffaber, P. D., \& Hetrick, W. P. (2005). Event-related potential correlates of task switching and switch costs. Psychophysiology, 42, 56 71

Killikelly, C., \& Szucs, D. (2013). Delayed development of proactive response preparation in adolescents: ERP and EMG evidence. Developmental Cognitive Neuroscience, 3, 33-45.

Kinder Associates LLC (2002). Programme information. Retrieved December 5, 2013, from www.wellnessworksinschools.com

Klonsky, E. D. (2007). The functions of deliberate self-injury: A review of the evidence. Clinical Psychology Review, 27, 226-239.

Kramer, A. F., Wickens, C. D., \& Donchin, E. (1985). Processing of stimulus properties: Evidence for dual-task integrality. Journal of Experimental Psychology: Human Perception Performance, 11, 393-408. doi:10.1037/0096-1523.11.4.393

Kuyken, W., Weare, K., Ukoumune, O. C., Vicary, R., Motton, N., Burnett, R., ... Huppert, F. (2013). Effectiveness of the Mindfulness in Schools programme: Non-randomised controlled feasibility study. British Journal of Psychiatry, 203, 126-131.

Ladouceur, C. D., Dahl, R. E., \& Carter, C. S. (2007). Development of action monitoring through adolescence into adulthood: ERP and source localisation. Developmental Science, 10, 874-891.

Larson, M. J., Steffen, P. R., \& Primosch, M. (2013). The impact of a brief mindfulness meditation intervention on cognitive control and errorrelated performance monitoring. Frontiers in Human Neuroscience, 7, 308. doi:10.3389/fnhum.2013.00308

LeDoux, J. E. (1995). Emotion: Clues from the brain. Annual Review of Psychology, 46, 209-235. doi:10.1146/annurev.ps.46.020195. 001233

Lee, H., Heller, A. S., van Reekum, C. M., Nelson, B., \& Davidson, R. J. (2012). Amygdala-prefrontal coupling underlies individual differences in emotion regulation. NeuroImage, 62, 1575-1581.

Luck, S. J. (2014). An introduction to the event-related potential technique (2nd ed.). Cambridge, MA: MIT Press.

Lutz, A., Slagter, H. A., Dunne, J. D., \& Davidson, R. J. (2008). Attention regulation and monitoring in meditation. Trends in Cognitive Sciences, 12, 163-169.

MacLeod, J. W., Lawrence, M. A., McConnell, M. M., Eskes, G. A., Klein, R. M., \& Shore, D. I. (2010). Appraising the ANT: Psychometric and theoretical considerations of the Attention Network Test. Neuropsychology, 24, 637-651.

Malinowski, P. (2013). Neural mechanisms of attentional control in mindfulness meditation. Frontiers in Neuroscience, 7, 8. doi:10.3389/ fnins. 2013.00008

Marks, A. D., Sobanski, D. J., \& Hine, D. W. (2010). Do dispositional rumination and/or mindfulness moderate the relationship between life hassles and psychological dysfunction in adolescents? Australian and New Zealand Journal of Psychiatry, 44, 831-838.

Meiklejohn, J., Phillips, C., Freedman, L., Griffin, M. L., Biegel, G., Roach, A., ... Saltzman, A. (2012). Intergrating mindfulness training into $\mathrm{K}-12$ education: Fostering the resilience of teachers and students. Mindfulness, 3, 291-307.

Mindful Schools Non-Profit Organisation (2010). Programme information. Retrieved December 5, 2013, from www.mindfulschools.org/

Mooneyham, B. W., \& Schooler, J. W. (2013). The costs and benefits of mind-wandering: A review. Canadian Journal of Experimental Psychology, 67, 11-18.

Moore, A., Gruber, T., Derose, J., \& Malinowski, P. (2012). Regular, brief mindfulness meditation practice improved electrophysiological markers of attentional control. Frontiers in Human Neuroscience, 6, 18. doi:10.3389/fnhum.2012.00018 
Moore, A., \& Malinowski, P. (2009). Meditation, mindfulness and cognitive flexibility. Consciousness and Cognition, 18, 176-186.

Mrazek, M. D., Smallwood, J., \& Schooler, J. W. (2012). Mindfulness and mind-wandering: Finding convergence through opposing constructs. Emotion, 12, 442-448. doi:10.1037/a0026678

Nagai, Y., Critchley, H. D., Featherstone, E., Fenwick, P. B. C., Trimble, M. R., \& Dolan, R. J. (2004). Brain activity relating to the contingent negative variation: An fMRI investigation. NeuroImage, 21, 1232-1241.

Oberle, E., Schonert-Reichl, K. A., Lawlor, M. S., \& Thomson, K. C. (2012). Mindfulness and inhibitory control in early adolescence. Journal of Early Adolescence, 32, 565-588.

Ochsner, K. N., Bunge, S. A., Gross, J. J., \& Gabrieli, J. D. E. (2002). Rethinking Feelings: An $f$ MRI study of the cognitive regulation of emotion. Journal of Cognitive Neuroscience, 14, 1215-1229. doi: $10.1162 / 089892902760807212$

Ochsner, K. N., \& Gross, J. J. (2005). The cognitive control of emotion. Trends in Cognitive Sciences, 9, 242-249. doi:10.1016/j.tics.2005. 03.010

Ortner, C. N. M., Kilner, S. J., \& Zelazo, P. D. (2007). Mindfulness meditation and reduced emotional interference on a cognitive task. Motivation and Emotion, 31, 271-283.

Overbeek, T. J. M., Nieuwenhuis, S., \& Ridderinkhof, K. R. (2005). Dissociable components of error processing: On the functional significance of the Pe vis-a-vis the ERN/Ne. Journal of PsychoPhysiology, 19, 319-329.

Palluel, E., Nougier, V., \& Olivier, I. (2010). Postural control and attentional demand during adolescence. Brain Research, 1358, 151-159.

Petersen, S. E., \& Posner, M. I. (2012). The attention system of the human brain: 20 years after. Annual Review of Neuroscience, 35, 73-89. doi:10.1146/annurev-neuro-062111-150525

Petter, M., McGrath, P. J., Chambers, C. T., \& Dick, B. D. (2014). The effects of mindful attention and state mindfulness on acute experimental pain among adolescents. Journal of Pediatric Psychology, 39, 521-531.

Picton, T. W., Bentin, S., Berg, P., Donchin, E., Hillyard, S. A., Johnson, R., ... Taylor, M. J. (2000). Guidelines for using human eventrelated potentials to study cognition: Recording standards and publication criteria. Psychophysiology, 37, 127-152. doi:10.1111/14698986.3720127

Polich, J. (2007). Updating P300: An integrative theory of P3a and P3b. Clinical Neurophysiology, 118, 2128-2148.

Posner, M. I. (2008). Measuring alertness. Annals of the New York Academy of Sciences, 1129, 193-199.

Posner, M. I., \& Petersen, S. E. (1990). The attention systems of the human brain. Annual Review of Neuroscience, 13, 25-40. doi:10. 1146/annurev.ne.13.030190.000325

Raes, F., Griffith, J. W., Van der Gucht, K., \& Williams, J. M. G. (2014). School-based prevention and reduction of depression in adolescents: A cluster-randomized controlled trial of a mindfulness group program. Mindfulness, 5, 477-486. doi:10.1007/s12671-013-0202-1

Ray Li, C. S., Chen, S. H., Lin, W. H., \& Yang, Y. Y. (2005). Attentional blink in adolescents with varying levels of impulsivity. Journal of Psychiatric Research, 39, 197-205.

Raymond, J. E., Shapiro, K. L., \& Arnell, K. M. (1992). Temporary suppression of visual processing in an RSVP task: An attentional blink? Journal of Experimental Psychology: Human Perception \& Performance, 18, 849-860. doi:10.1037/0096-1523.18.3.849

Raz, A., \& Buhle, J. (2006). Typologies of attentional networks. Nature Reviews Neuroscience, 7, 367-379.

Rellecke, J., Sommer, W., \& Schacht, A. (2012). Does processing of emotional facial expressions depend on intention? Time-resolved evidence from event-related brain potentials. Biological Psychology, 90, 23-32.

Robertson, I. H., Manly, T., Andrade, J., Baddeley, B. T., \& Yiend, J. (1997). Oops! Performance correlates of everyday attentional failures in traumatic brain injured and normal subjects. Neuropsychologia, 35, 747-758.

Roeser, R. W., \& Peck, S. C. (2009). An education in awareness: Self, motivation, and self-regulated learning in contemplative perspective. Educational Psychology, 44, 119-136.

Ros, T., Théberge, J., Frewen, P. A., Kluetsch, R., Densmore, M., Calhoun, V. D., \& Lanius, R. A. (2013). Mind over chatter: Plastic up-regulation of the fMRI salience network directly after EEG neurofeedback. NeuroImage, 65, 324-335.

Saltzman, A., \& Goldin, P. (2008). Mindfulness based stress reduction for school-aged children. In S. C. Hayes \& L. A. Greco (Eds.), Acceptance and mindfulness interventions for children, adolescents, and families (pp. 139-161). Oakland, CA: Context Press/New Harbinger.

Sauer, S., Walach, H., \& Kohls, N. (2011). Gray's Behavioural Inhibition System as a mediator of mindfulness towards well-being. Personality and Individual Differences, 50(4), 506-511.

Schaefer, A., Pottage, C. L., \& Rickart, A. J. (2011). Electrophysiological correlates of remembering emotional pictures. NeuroImage, 54, 714-724.

Scherer, K. R. (2000). Psychological models of emotion. In J. Borod (Ed.), The neuropsychology of emotion (pp. 137-162). Oxford, UK: Oxford University Press.

Schonert-Reichl, K. A., \& Lawlor, M. S. (2010). The effects of a mindfulness-based education program on pre- and early adolescents' well-being and social and emotional competence. Mindfulness, 1, 137-151.

Segal, Z., Williams, J. M. G., \& Teasdale, J. D. (2002). Mindfulnessbased cognitive therapy for depression: A new approach to relapse prevention. New York, NY: Guilford Press.

Shackman, A. J., Maxwell, J. S., McMenamin, B. W., Greischar, L. L., \& Davidson, R. J. (2011). Stress potentiates early and attenuates late stages of visual processing. Journal of Neuroscience, 31, 11561161. doi:10.1523/JNEUROSCI. 3384-10.2011

Shackman, A. J., Sarinopoulos, I., Maxwell, J. S., Pizzagalli, D. A., Lavric, A., \& Davidson, R. J. (2006). Anxiety selectively disrupts visuospatial working memory. Emotion, 6, 40-61.

Shapiro, S. L., Carlson, L. E., Astin, J. A., \& Freedman, B. (2006). Mechanisms of mindfulness. Journal of Clinical Psychology, 62, 373-386.

Siegel, R. D., Germer, C. K., \& Olendzki, A. (2008). Mindfulness: What is it? Where did it come from? In F. Didonna (Ed.), Clinical handbook of mindfulness (pp. 17-36). New York, NY: Springer.

Sitges, C., Garcia-Herrera, M., Pericas, M., Collado, D., Truyols, M., \& Montoya, P. (2007). Abnormal brain processing of affective and sensory pain descriptors in chronic pain patients. Journal of Affective Disorders, 104, 73-82.

Slagter, H. A., Lutz, A., Greischar, L. L., Francis, A. D., Nieuwenhuis, S., Davis, J. M., \& Davidson, R. J. (2007). Mental training affects distribution of limited brain resources. PLoS Biology, 5, 12281235. doi:10.1371/journal.pbio.0050138

Smallwood, J., Beach, E., Schooler, J. W., \& Handy, T. C. (2008). Going AWOL in the brain: Mind wandering reduces cortical analysis of external events. Journal of Cognitive Neuroscience, 20, 458-469. doi:10.1162/jocn.2008.20037

Spear, L. P. (2013). Adolescent neurodevelopment. Journal of Adolescent Health, 52, S7-S13.

Steinberg, L. (2005). Cognitive and affective development in adolescence. Trends in Cognitive Sciences, 9, 69-74.

Steinberg, L. (2010). A behavioural scientist looks at the science of adolescent brain development. Brain and Cognition, 72, 160-164.

Stevens, C., Fanning, J., Coch, D., Sanders, L., \& Neville, H. (2008). Neural mechanisms of selective auditory attention are enhanced by computerized training: Electrophysiological evidence from language-impaired and typically developing children. Brain Research, 1205, 55-69. 
Stroop, J. R. (1935). Studies of interference in serial verbal reactions. Journal of Experimental Psychology, 18, 643-662. doi:10.1037/ 0096-3445.121.1.15

Sutton, S., Braren, M., Zubin, J., \& John, E. R. (1965). Evoked-potential correlates of stimulus uncertainty. Science, 150, 1187-1188.

Tang, Y.-Y., Hölzel, B. K., \& Posner, M. I. (2015). The neuroscience of mindfulness meditation. Nature Reviews Neuroscience, 16, 213 225.

Taylor, V. A., Grant, J., Daneault, V., Scavone, G., Breton, E., RoffeVidal, S., ... Beauregard, M. (2011). Impact of mindfulness on the neural responses to emotional pictures in experienced and beginner meditators. NeuroImage, 57, 1524-1533.

Teper, R., \& Inzlicht, M. (2013). Meditation, mindfulness and executive control: The importance of emotional acceptance and brain-based performance monitoring. Social Cognitive and Affective Neuroscience, 8, 85-92. doi:10.1093/scan/nss045

Teper, R., Segal, Z., \& Inzlicht, M. (2013). Inside the mindful mind: How mindfulness enhances emotion regulation through improvements in executive control. Current Directions in Psychological Science, 22, 449-454.

The Hawn Foundation (2011). Programme information. Retrieved December 5, 2013, from http://thehawnfoundation.org/mindup/

Unsworth, N., McMillan, B. D., Brewer, G. A., \& Spillers, G. J. (2012). Everyday attention failures: An individual differences investigation. Journal of Experimental Psychology: Learning, Memory, and Cognition, 38, 1765-1772.

Van Leijenhorst, L., Gunther Moor, B., Op de Macks, Z. A., Rombouts, S. A. R. B., Westenberg, P. M., \& Drone, E. A. (2010). Adolescent risky decision making: Neurocognitive development of reward and control regions. Neurolmage, 51, 345-355.

van Veen, V., \& Carter, C. S. (2002). The timing of action-monitoring processes in the anterior cingulate cortex. Journal of Cognitive Neuroscience, 14, 593-602. doi:10.1162/08989290260045837

Walter, W. G., Cooper, R., Aldridge, V. J., McCallum, W. C., \& Winter, A. L. (1964). Contingent negative variation: An electric sign of sensori-motor association and expectancy in the human brain. Nature, 203, 380-384.

Watter, S., Geffen, G. M., \& Geffen, L. B. (2001). The $n$-back as a dualtask: P300 morphology under divided attention. Psychophysiology, 38, 998-1003.

Westbrook, C., Creswell, J. D., Tabibnia, G., Julson, E., Kober, H., \& Tindle, H. A. (2013). Mindful attention reduces neural and selfreported cue-induced craving in smokers. Social Cognitive and Affective Neuroscience, 8, 73-84.

Zenner, C., Herrnleben-Kurz, S., \& Walach, H. (2014). Mindfulnessbased interventions in schools - A systematic review and meta-analysis. Frontiers in Psychology, 5(603), 1-20. doi:10.3389/fpsyg. 2014.00603

Zhang, W., Lu, J., Fang, H., Pan, X., Zhang, J., \& Wang, D. (2012). Late positive potentials in affective picture processing during adolescence. Neuroscience Letters, 510, 88-92.

Zhang, W., Lu, J., Ni, Z., Liu, X., Wang, D., \& Shen, J. (2013). Harm avoidance in adolescents modulates late positive potentials during affective picture processing. International Journal of Developmental Neuroscience, 31, 297-302. 